\title{
Experimental study of lateral resistance of bolted joints using Japanese cedar (Cryptomeria japonica) treated with resin impregnation
}

\author{
Keita Ogawa ${ }^{1 *}$, Satoshi Fukuta ${ }^{2}$ and Kenji Kobayashi ${ }^{1}$
}

\begin{abstract}
The development of wooden joints possessing high resistance performance has become an important issue for the construction of newer buildings. This study attempts to strengthen the lateral resistance of bolted joints using the previously reported plasticizing technique. This technique consists of two processing stages: incising the surface of the wood using an ultraviolet wavelength short-pulse laser and impregnating the resin into the incised area. This technique makes it possible to plasticize only a local part of the wood surface. Bolted joint specimens were assembled using plasticized wood around the bolt hole, and the lateral tests were conducted. Acrylic monomer and urethane prepolymer were used as the impregnating resins and their incision depths were set as 4 and $10 \mathrm{~mm}$. When the lateral load acted parallel to the grain, changes in the lateral resistance characteristics were observed, especially for the stiffness and yield load. For example, when acryl was used, and the incision depth was $10 \mathrm{~mm}$, an increment of $73 \%$ in the yield load was observed, as compared to the non-impregnated specimens. The specimen groups impregnated with acryl exhibited greater changes in their properties than those using urethane. When loaded perpendicular to the grain, an increase in properties were observed; however, these increments were lower than those of the groups loaded parallel to the grain.
\end{abstract}

Keywords: Bolted joint, Lateral resistance, Wood plastic composite, Resin impregnation

\section{Introduction}

Recently, there has been an increase in the interest for large-scale wooden buildings owing to the demand of sustainable building options. Lateral resistance of joints plays an important role in the structural performance of buildings. Bolts are one of the commonly used fasteners for joining wooden members. Bolted joints have been used in wooden buildings worldwide for a long time. The external forces acting on buildings exert a lateral load on these bolted joints. Therefore, it is necessary to understand the lateral resistance of these joints. Consequently,

\footnotetext{
*Correspondence: ogawa.keita@shizuoka.ac.jp

${ }^{1}$ College of Agriculture, Academic Institute, Shizuoka University, 836

Ohya, Suruga-ku, Shizuoka 422-8529, Japan

Full list of author information is available at the end of the article
}

many studies have been conducted, and a review of such studies has been reported by Sawata [1,2].

To ensure the building safety, the development of wooden joints having higher lateral resistance is essential. An example of load-deformation response for a laterally load acting on a bolted joint is depicted in Fig. 1 . Joint response is a combination of localize wood crushing and bolt bending. The wood members slip and the bolt undergoes bending; moreover, embedment deformation was observed in a localized area of the wood member (as indicated by the brown-colored area in the figure). Based on this observation, reinforcing a localized area of the wood against crushing appears to be an effective method for developing a bolted joint possessing high-lateral performance. 


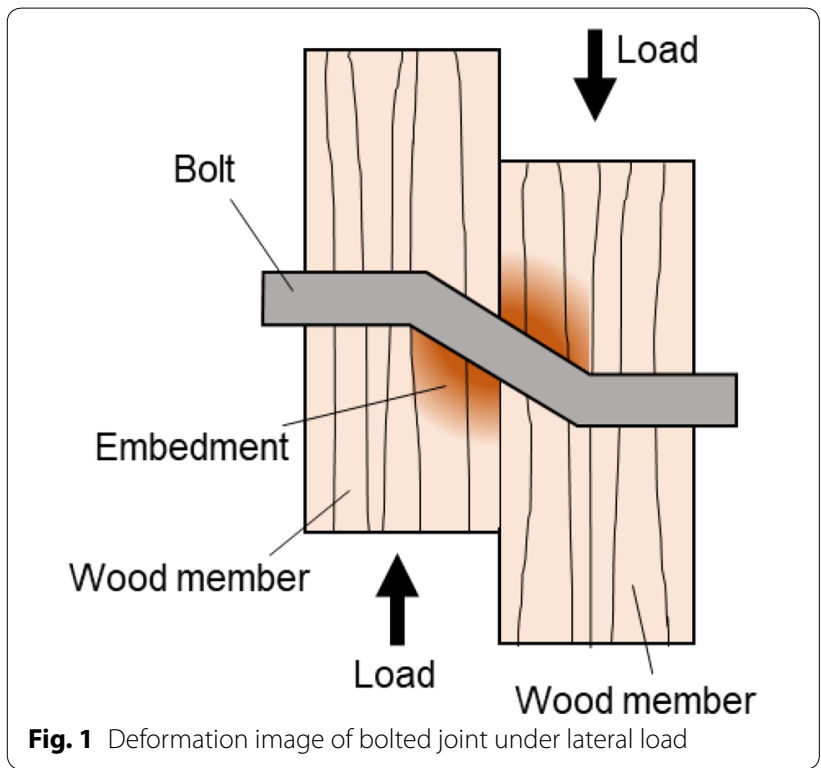

There are some techniques for improving the mechanical properties of wood. Surface densification is one such well-known method. Many researchers have reported improvements in the mechanical properties of wood through surface densification [3-8], and it is predicted that the use of densified wood in bolted joints will improve the lateral properties of these joints. However, when surface densification is applied to structural materials, substantial treatment is required because the material is generally large and an extremely high compression load is required. Another approach is the local improvement of the embedment properties (Fig. 1).

The authors saw potential in the plasticizing technique as one viable option for localize improvement of bearing properties. Fukuta et al. [9] used an ultravioletwavelength short-pulse laser (hereinafter referred to as a UV laser) to create microscopic incisions on the wood surface and attempted to improve the physical properties by plasticizing the surface layer using impregnating resins. This technique enables plasticizing local areas of the wood surface. The study confirmed sufficient impregnation based on an observation of the scanning electron microscope (SEM) images, and reported that the Brinell hardness and indentation depth against impact load were significantly improved because the resins filled the cells of the wood. The authors expected that impregnation would also be efficient for the improvement of lateral resistance of joints, because the embedment resistance would improve due to the impregnation of resins. An additional advantage is that it can be applied to local areas of the wood surface and involves minimal unnecessary treatment work.
This study attempts to develop high-capacity bolted joints against lateral load by using wood treated with resin impregnation on its surface. A lateral test was conducted with the joint specimens, and the experimental results are reported.

\section{Materials and methods Material preparation}

Solid pieces of Japanese cedar (Cryptomeria japonica D. Don) harvested from Shizuoka prefecture were used for the joint specimens. The size of the specimens was $60 \times 105 \times 300 \mathrm{~mm}$.

The measured density divided the wood pieces into ten groups, making sure that the difference in density between groups was minimized. Six replicates were assigned to each group. The densities of the center and side members are listed in Table 1.

Second, the materials were treated with resin impregnation on their surfaces. Microscopic incisions were created on the solid wood using a UV laser. As can be seen from the dotted areas shown in Fig. 2, the incisions were created in square areas of size $30 \times 30 \mathrm{~mm}$. The incisions were not only on the top surface, but also on the reverse side. Diode-pumped solid-state Q-switched lasers (Spectra-Physics, Talon355-15SH) were used. Using a Galvano scanner, the incision pattern (Fig. 3) was drawn, with a hole density of 667 holes $/ \mathrm{cm}^{2}$. The target incision depth was set to either 4 or $10 \mathrm{~mm}$, and other laser irradiation parameters are shown in Table 2, which were determined according to a previous study [9]. The processing time for each square was 32 or $134 \mathrm{~s}$ for target depths of 4 and $10 \mathrm{~mm}$, respectively.

Finally, the wood was impregnated with resin. Two types of resin were used in this study. The first was acrylic monomer (Toeikasei Co., Ltd., DIAKITE PF-2730) (hereafter, acryl). 0.6 parts by weight of 2,2'-azobisisobutyronitrile was included as a polymerization initiator. The acryl was impregnated on the incised areas using a paint brush. This application was continued until impregnation to the complete depth of the incised area was confirmed visually. As acryl polymerizes in an anaerobic environment, a heating press machine was used with a temperature of $140{ }^{\circ} \mathrm{C}$ but with no pressure applied (the surface of the solid wood only touched the heating plate of the machine). The heating time was approximately $30 \mathrm{~min}$. The second resin used was urethane prepolymer (Kotobukikakou Co., Ltd., PS-NY6) (hereinafter, urethane). The evaporation residue of urethane is $40 \%$. As in the case of acryl, it was applied with a paint brush until full impregnation was visually observed. Since urethane is a cold-setting polymer, the solid wood was left to stand for over 1 week after impregnation for curing. 
Table 1 Summary of joint specimen groups

\begin{tabular}{|c|c|c|c|c|c|}
\hline \multirow[t]{2}{*}{ Group } & \multicolumn{2}{|l|}{ Density $^{\mathrm{a}}\left(\mathrm{kg} / \mathrm{m}^{3}\right)$} & \multirow[t]{2}{*}{ Loading direction } & \multirow[t]{2}{*}{ Resin } & \multirow{2}{*}{$\begin{array}{l}\text { Incision } \\
\text { depth } \\
(\mathrm{mm})\end{array}$} \\
\hline & Center member & Side member & & & \\
\hline A & $384.6 \pm 10.2$ & $349.2 \pm 19.4$ & Parallel & None & - \\
\hline B & $384.5 \pm 9.3$ & $349.7 \pm 18.2$ & Parallel & Acryl & 4 \\
\hline C & $384.4 \pm 8.4$ & $349.7 \pm 18.1$ & Parallel & Acryl & 10 \\
\hline D & $384.3 \pm 8.4$ & $349.9 \pm 17.6$ & Parallel & Urethane & 4 \\
\hline$E$ & $385.1 \pm 8.1$ & $348.8 \pm 18.7$ & Parallel & Urethane & 10 \\
\hline $\mathrm{F}$ & $384.8 \pm 9.9$ & $349.6 \pm 18.7$ & Perpendicular & None & - \\
\hline G & $384.4 \pm 8.9$ & $349.7 \pm 18.2$ & Perpendicular & Acryl & 4 \\
\hline $\mathrm{H}$ & $384.3 \pm 8.7$ & $349.7 \pm 18.0$ & Perpendicular & Acryl & 10 \\
\hline । & $385.1 \pm 8.2$ & $349.7 \pm 17.6$ & Perpendicular & Urethane & 4 \\
\hline J & $385.2 \pm 8.3$ & $349.2 \pm 18.2$ & Perpendicular & Urethane & 10 \\
\hline
\end{tabular}

a The values mean average \pm standard deviation

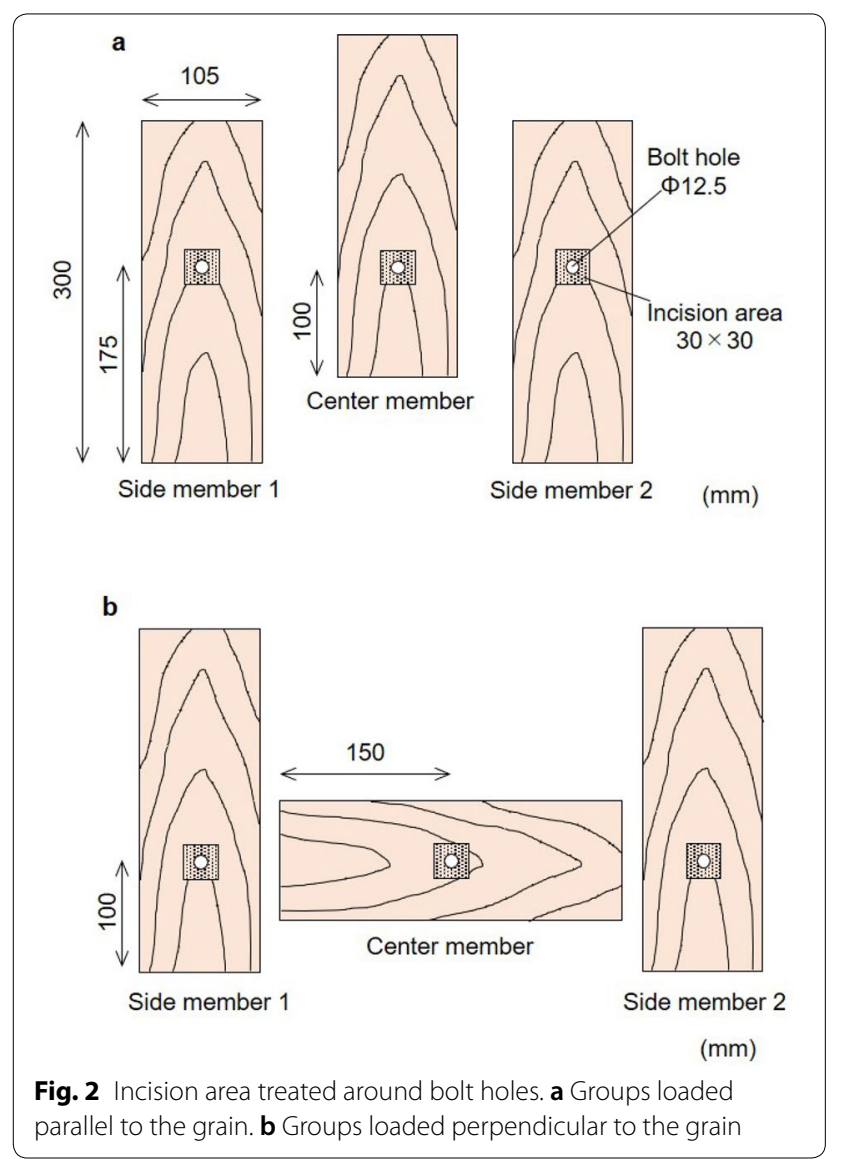

The impregnation level of the resins was evaluated using the parameter $W$ obtained by the following equation:

$$
W=\frac{m_{1}-m_{0}}{A \cdot d},
$$

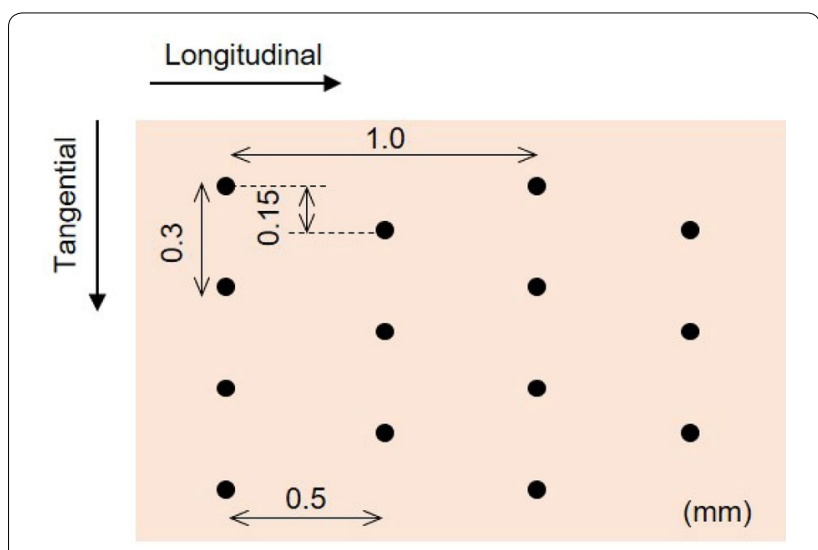

Fig. 3 Incision pattern

Table 2 Laser irradiation parameters

\begin{tabular}{lll}
\hline & Group B, D, G, I & Group C, E, H, J \\
\hline Wavelength $(\mathrm{nm})$ & 355 & 355 \\
Pulse width $(\mathrm{ns})$ & 25 & 25 \\
Pulse energy $(\mu \mathrm{J})$ & 260 & 260 \\
Pulse repetition rate $(\mathrm{kHz})$ & 50 & 50 \\
Power $(W)$ & 13 & 13 \\
Theoretical focal spot diameter $(\mu \mathrm{m})$ & 22.6 & 22.6 \\
Irradiation time per 1 hole $(\mathrm{ms})$ & 3 & 20 \\
\hline
\end{tabular}

where $m_{0}$ and $m_{1}$ are the mass of the pieces of solid wood before and after impregnation, respectively. $A$ is the area of incised portion (i.e., $900 \mathrm{~mm}^{2}$ ), and $d$ is the target depth $(4 \mathrm{~mm}$ or $10 \mathrm{~mm})$. 


\section{Joint specimen}

The joint specimens were assembled according to standard for structural design of timber structure [10], and similar description is shown in ASTM D5652-12 [11]. The joint specimens loaded parallel and perpendicular to the grain are shown in Fig. 4. Three pieces of solid wood were joined with a bolt of diameter $12 \mathrm{~mm}$. The washer size was $40 \mathrm{~mm}$ in diameter and $3.2 \mathrm{~mm}$ in thickness, and was selected according to the standard [12]. When assembling the joint specimen, all pieces of solid wood were placed so that the sapwood was facing the bolt head (in Fig. 4, sapwood is on the left side, and heartwood is on the right side). Tightening of the bolt was conducted by hand and continued until the washer was embedded into the wood surface by $1.0-1.5 \mathrm{~mm}$ as observed visually. There was no treatment for reducing the friction between the center and side members. In ASTM D5652-15, the nut should be controlled to "finger tightness". While, in practice, nuts are commonly over-tightened and our tests reflect that in service condition. It is well known that the strong tightness affects the test result and it should be clarified quantitatively in the future.

The specimen groups are summarized in Table 1. Groups A and F were prepared as control specimens. For the impregnated groups, two types of resin-acryl and urethane-and two incision depths $-4 \mathrm{~mm}$ and $10 \mathrm{~mm}$-were prepared; thus, a total of ten groups were tested. There were six test specimens in each group; however, for groups A, C, and J, only five measurements were obtained owing to errors during the tests.

\section{Lateral joint test}

The lateral tests were conducted as shown in the photographs in Fig. 4. An oil pressure control testing machine (Maekawa Testing Machine MFG Co., Ltd., IPU-B43) was used.

For the test involving the loading parallel to the grain (Fig. 4a), the joint specimen was set on the rigid plate, and a downward load was applied on the top of the center member. The load was measured using a load cell (Tokyo

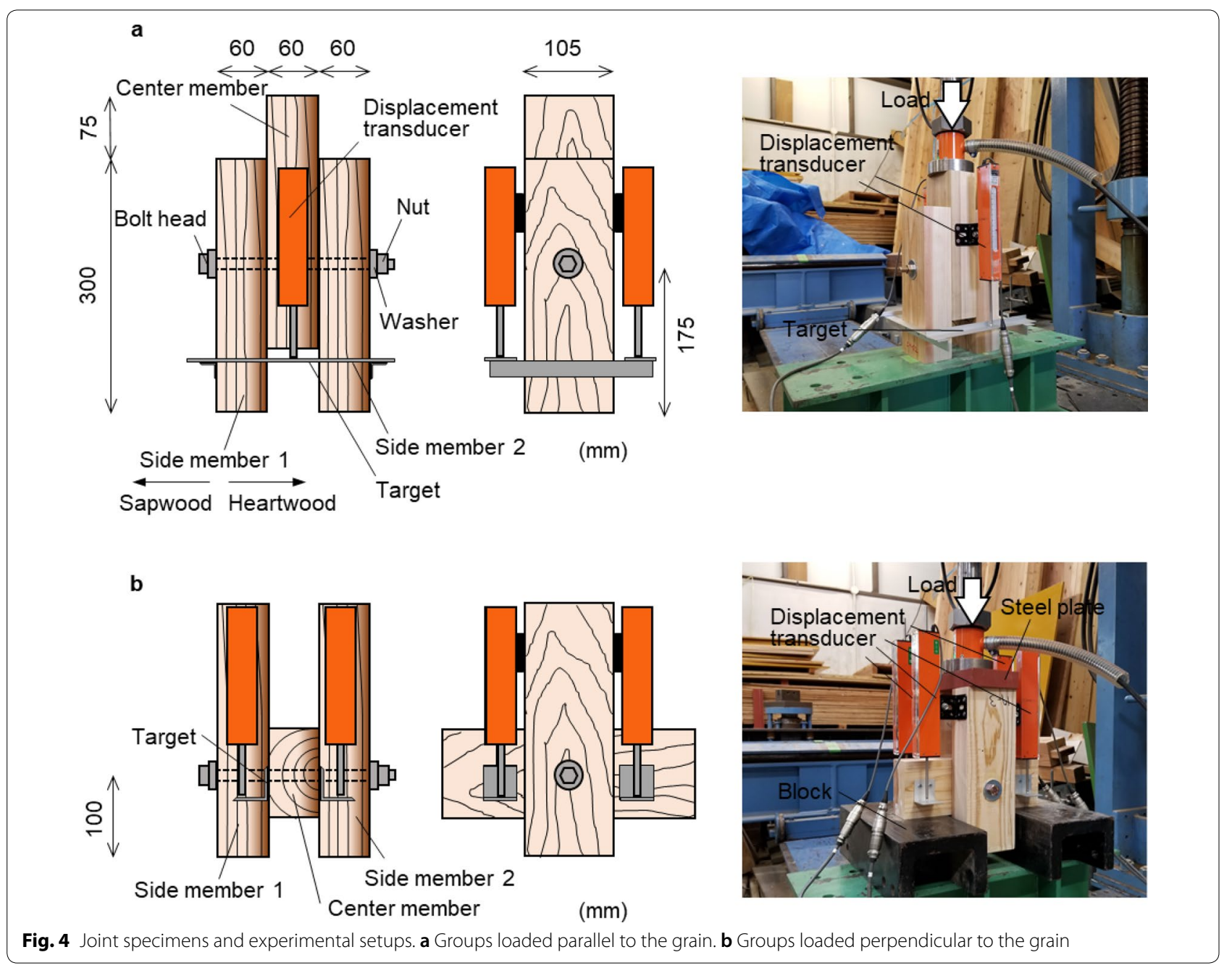


Measuring Instruments Laboratory Co., Ltd., KCM100KNA, capacity: $100 \mathrm{kN}$ ). The slip between the center member and side members was measured using two displacement transducers (Tokyo Measuring Instruments Laboratory Co., Ltd., SDP-100C, capacity: $100 \mathrm{~mm}$ ) attached to both sides of the center member and the displacement transducer targets attached to the side members. The slip value of the joint was obtained by averaging the two values obtained via the displacement transducers.

For the test with loading perpendicular to the grain (Fig. 4b), the joint specimen was set on the steel block, and the load was applied downward to the top of the side members with a steel plate. The slip was measured with four displacement transducers attached to the side members, and the average value was used for the slip value of the joint.

In both tests, the load was applied at a speed of approximately $2 \mathrm{~mm} / \mathrm{min}$. After reaching a maximum value, the load was continuously applied until it decreased to $80 \%$ of the maximum.

\section{Results and discussion}

\section{Impregnation amount}

The average and standard deviation of the impregnation level $W$ are shown in Fig. 5; in sapwood, the values exceed $2000 \mathrm{~kg} / \mathrm{m}^{3}$. The values of $W$ were compared to the theoretical maximum impregnation level $W_{\max }$ calculated using the following equation:

$$
W_{\max }=\left(1-\frac{\rho_{\mathrm{D}}}{\rho_{\mathrm{S}}}\right) \times \rho_{\mathrm{L}}
$$

where $\rho_{\mathrm{D}}$ is the oven-dried density of the test specimen, $\rho_{\mathrm{S}}$ is the density of wood substance, and $\rho_{\mathrm{L}}$ is the density of the resin liquid. Here, $\rho_{\mathrm{D}}$ was $321 \mathrm{~kg} / \mathrm{m}^{3}$, which was the average value of oven-dried pieces of solid wood from groups $\mathrm{A}$ and $\mathrm{F}$ (non-impregnated group), $\rho_{\mathrm{S}}$ was

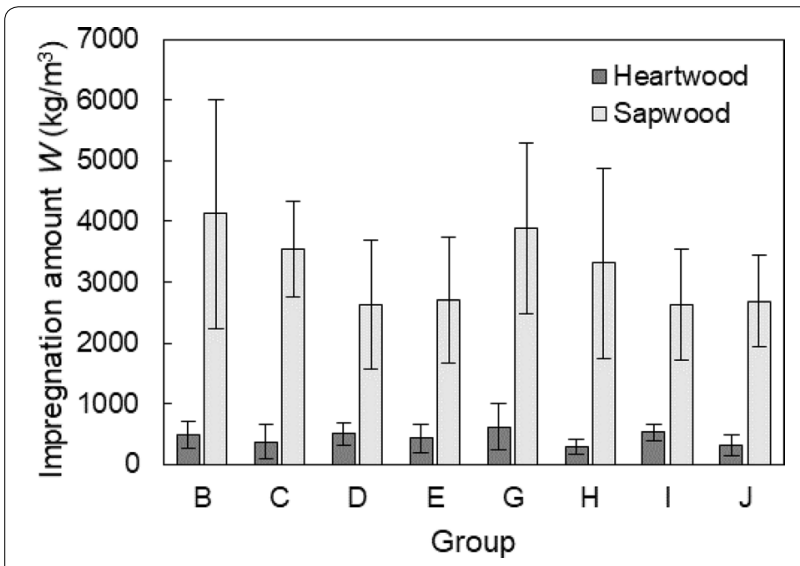

Fig. 5 Average and standard deviation of impregnation amount
$1500 \mathrm{~kg} / \mathrm{m}^{3}$, and $\rho_{\mathrm{L}}$ was $1070 \mathrm{~kg} / \mathrm{m}^{3}$ and $950 \mathrm{~kg} / \mathrm{m}^{3}$ for acryl and urethane, respectively. The calculated results of $W_{\max }$ were $841 \mathrm{~kg} / \mathrm{m}^{3}$ for acryl and $747 \mathrm{~kg} / \mathrm{m}^{3}$ for urethane. The $W$ values in sapwood were greater than $W_{\max }$. Therefore, it is assumed that the resin spread through the lumen of the tracheid or the intercellular space of cells. It should be recognized that this study set the impregnation area as $30 \times 30 \mathrm{~mm}$; however, in reality, the resin was not restricted to this area and spread more widely. Because the values of $W$ exceed the $W_{\max }$ greatly, it is assumed to be difficult to understand the impregnation amount with parameter $W$ in Eq. (1) which is widely used when evaluating the impregnation of chemical liquid. The new method or parameter is required.

The values of $W$ in heartwood were smaller than those of sapwood. In general, the heartwood compounds adhere on the pits in heartwood [13], which may reduce the spread of resin through the lumen.

Figure 6 shows examples of the deformation of the bolt observed after the lateral tests. In the control groups (A and F), the largest bending deflection of the bolt is represented by a black arrow and positioned at almost the center of the width of the center member. In the impregnated groups, the largest deflections were observed slightly closer to the sapwood side of the center member. The reason for this is assumed to be that more resin was impregnated in the sapwood, resulting in a larger bending load acting on this part of the bolt. This result suggests that the impregnation level affects the lateral resistance of bolted joints. To clarify the embedment behavior precisely, it is important to understand how the resins spread in the wood, which may be an important research theme for the future.

\section{Load-slip relationships}

The load-slip relationships obtained from the lateral tests are shown in Figs. 7 and 8. In all groups, an increase in load without any slip was observed at the start of the tests. This appeared due to the friction between members. When the load reached approximately $4-5 \mathrm{kN}$, the slip started increasing. After this, the load increased linearly with an increase in slip. When the load reached the yielding point, the slope between the load and slip gradually decreased. After reaching the maximum load, the load value decreased and failure occurred. The failure mode is shown in Fig. 9; splitting in the center members was observed for all specimens.

In the groups loaded parallel to the grain (Fig. 7), group A began to yield at approximately $15 \mathrm{kN}$. The maximum load was approximately $25 \mathrm{kN}$, at a slip of $25 \mathrm{~mm}$. Failure (which was defined as the point where the load decreased to $80 \%$ of the maximum) occurred at greater than $30 \mathrm{~mm}$ in almost all specimens; therefore, a high deformation 

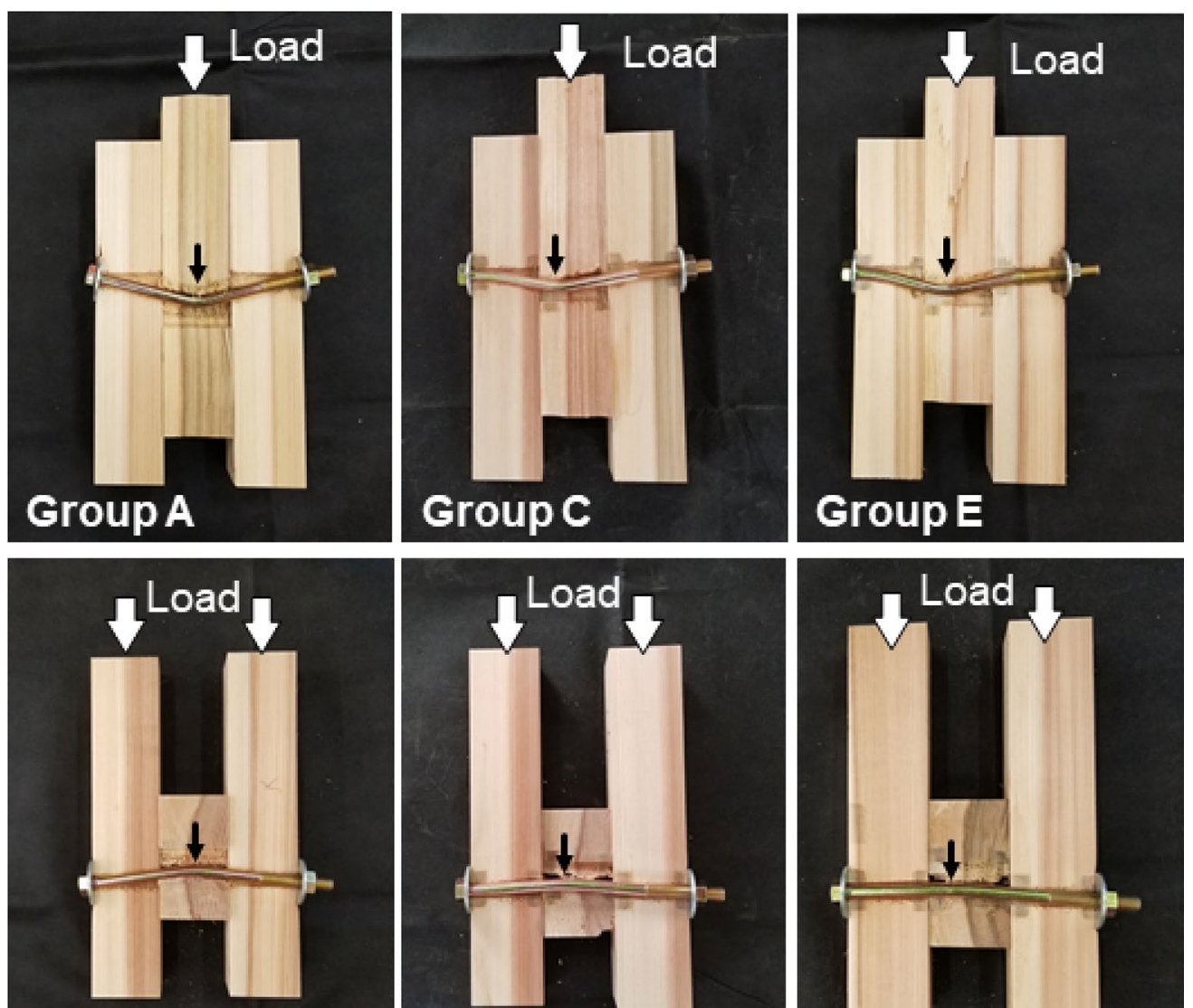

\section{Group F}
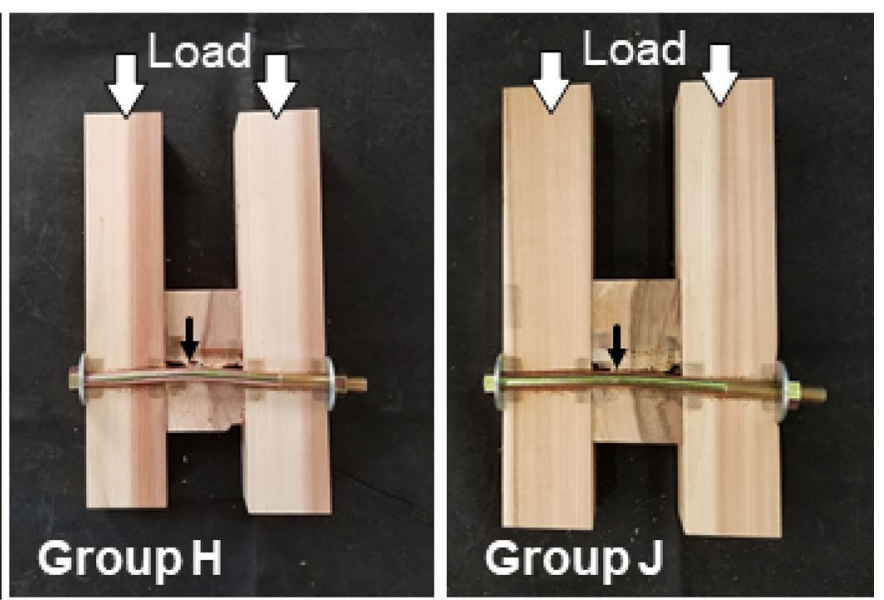

Fig. 6 Examples of bending deformation of bolts occurred in the joint specimens
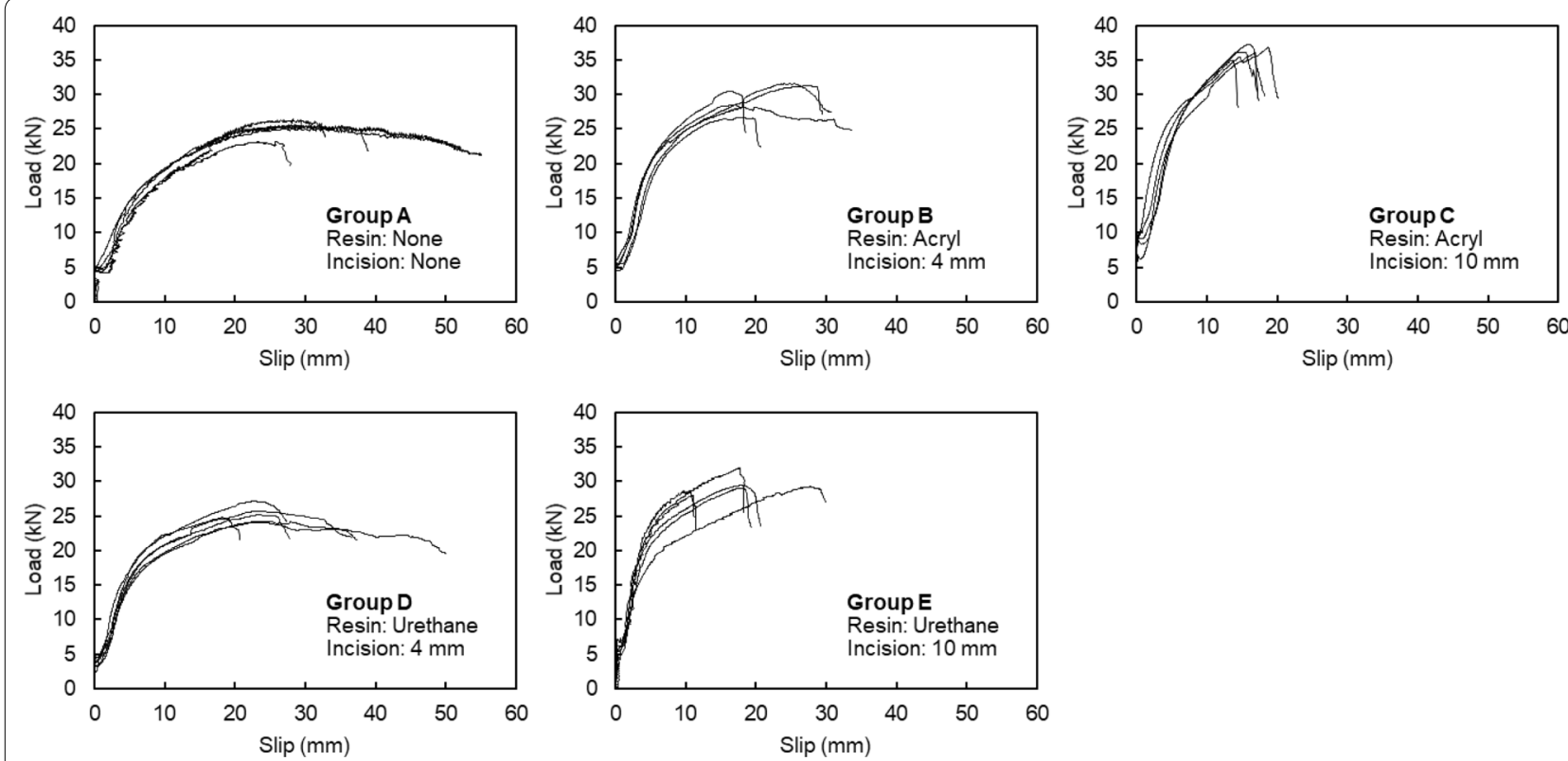

Fig. 7 Load-slip relationships of groups loaded parallel to the grain 

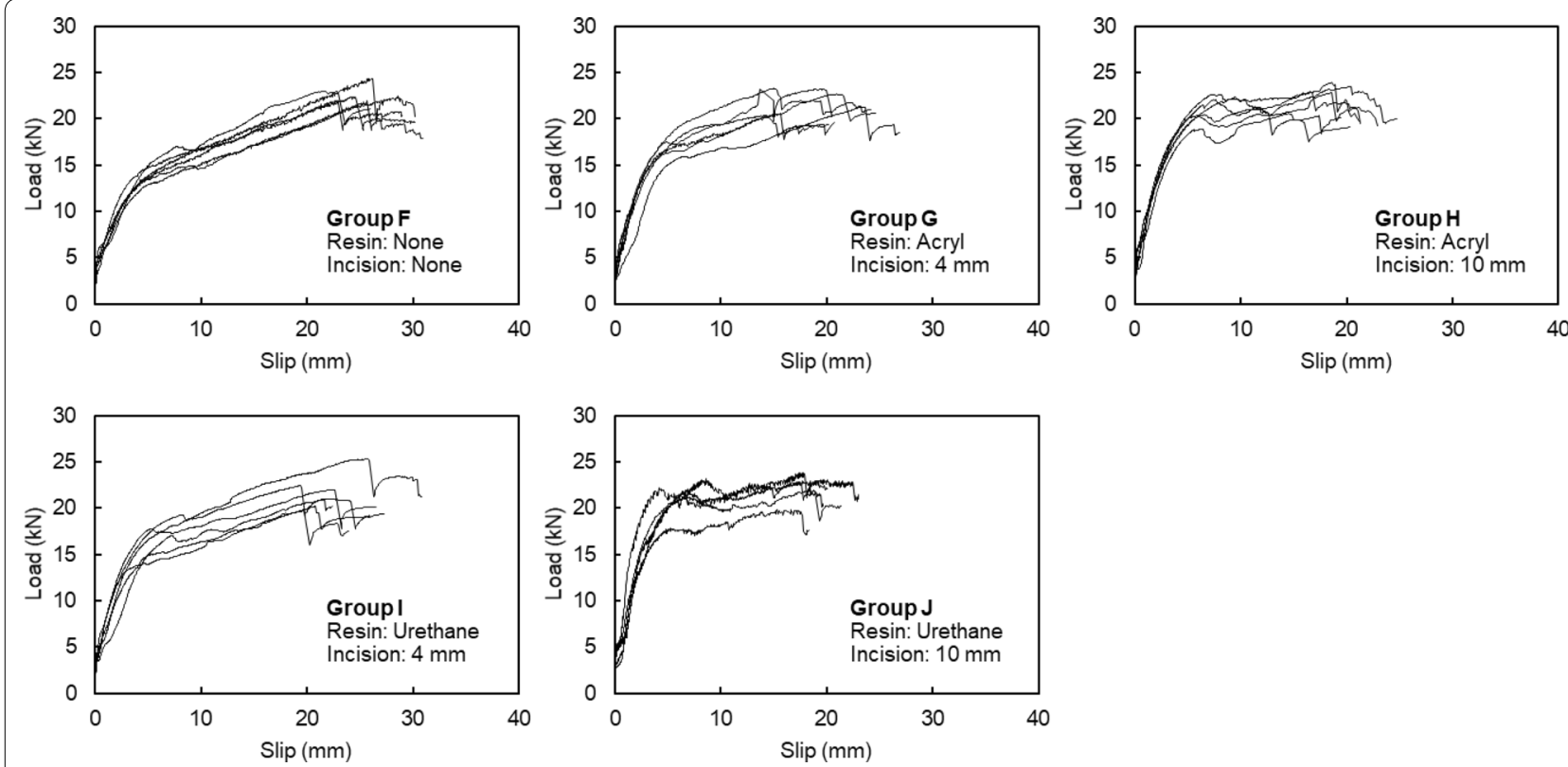

Fig. 8 Load-slip relationships of groups loaded perpendicular to the grain
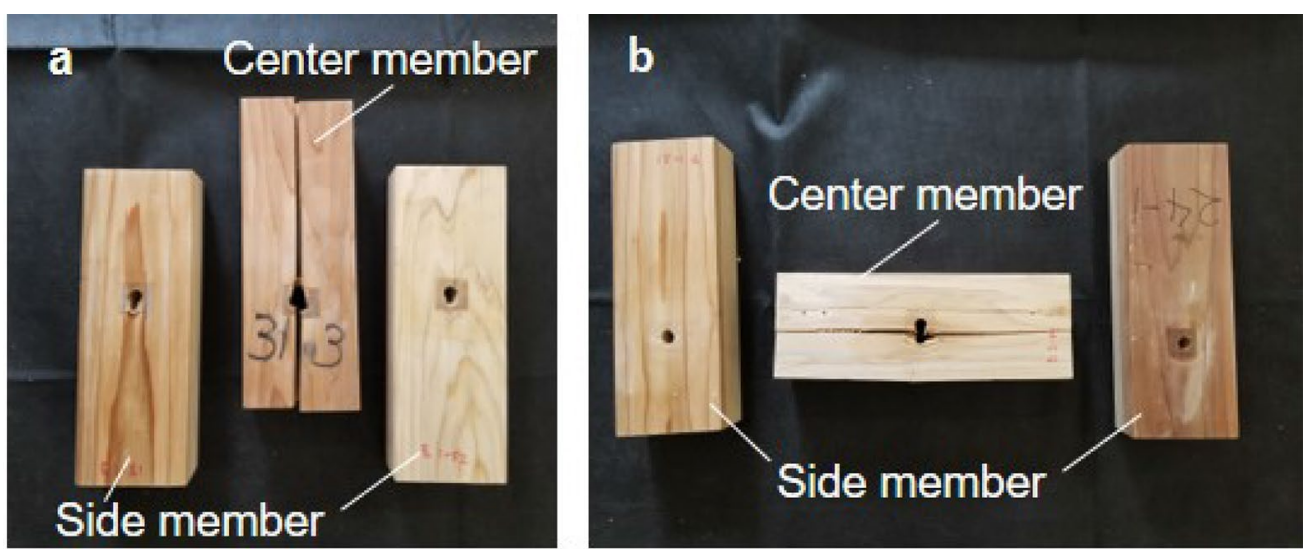

Fig. 9 Splitting failure of center member. a Groups loaded parallel to the grain. $\mathbf{b}$ Groups loaded perpendicular to the grain

capacity was observed. Comparing A to the other groups, the impregnated groups yield a higher stiffness and yielding load, and the maximum loads appear at the lower slip. A comparison of the types of impregnated resin (Group B to $\mathrm{D}$ and Group $\mathrm{C}$ to $\mathrm{E}$ ) reveal that a higher stiffness and maximum load was achieved in the groups using acryl, and a higher deformation capacity was observed in the groups using urethane.

In the groups loaded perpendicularly to the grain (Fig. 8), group F began to yield at approximately $13 \mathrm{kN}$. After yielding, the load gradually increased and the maximum load was approximately $20 \mathrm{kN}$. A sudden decrease in the load was observed immediately after the maximum load. In the impregnated groups, higher stiffness values were observed. After yielding, the load was almost constant until the joints failed, especially in groups $\mathrm{H}$ and $\mathrm{J}$. All the impregnated groups exhibited deformation capacities that were almost identical to that of group F.

\section{Characteristics values}

The perfect elasto-plastic model [14] was applied to the load-slip relationships (Figs. 7 and 8). The model is used for evaluating the characteristics values of structural elements including timber joints [15-18]. The method for obtaining the characteristics values is explained below and Fig. 10. The black line means the load-slip 


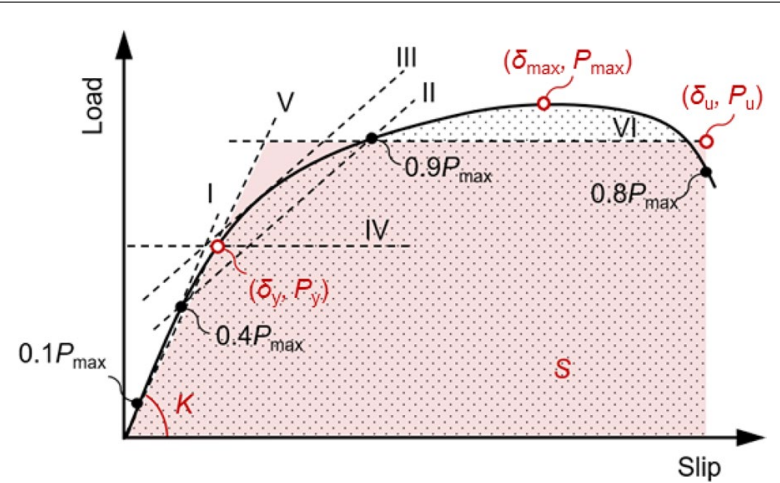

Fig. 10 Method for obtaining the characteristics values by perfect elasto-plastic model

relationship obtained by the test. $P_{\max }$ and $\delta_{\max }$ mean maximum load and slip at maximum load, respectively. At first, a direct line is drawn between $0.1 P_{\max }$ and $0.4 P_{\max }$, and $0.4 P_{\max }$ and $0.9 P_{\max }$ on the relationship. The former and later are named Line I and II, respectively. Line II shifts until it meets the load-slip relationship, and the shifted line is named Line III. The new line parallel to the horizontal axis which passing through the intersection of Line I and III is drawn and named Line IV. The intersection of Line IV with the load-slip relationship is determined as yield point, and the abscissa and ordinate of the point are slip at yielding $\delta_{\mathrm{y}}$ and yield load $P_{\mathrm{y}}$, respectively. The line connecting origin and yield point is named Line $\mathrm{V}$, and the slope of Line $\mathrm{V}$ is determined as stiffness $K$. Next, the slip at ultimate load $\delta_{\mathrm{u}}$ is determined as the abscissa of point when the load is decreased to $0.8 P_{\max }$ after surpassing the maximum load. Then the energy on the load-slip relationship from origin to $\delta_{\mathrm{u}}$ (dotted part) is found and it is symbolled as $S$. The Line VI parallel to the horizontal axis is drawn so that the area of trapezoid which consists of Line V, Line VI, horizontal axis, and $X=\delta_{\mathrm{u}}$ (red part in Fig. 10) becomes same with energy $S$. The ordinate of Line VI is determined as ultimate load $P_{\mathrm{u}}$. The average and standard deviation are shown in Table 3. This result enables a quantitative evaluation of the strengthening effect of resin impregnation. Figure 11 shows the ratio of the impregnated groups to the control group. The ratio values were calculated using each average value in Table 3.

In the groups loaded parallel to the grain (Fig. 11a), clear improvements were observed in the selected parameters: stiffness $K$, yield load $P_{\mathrm{y}}$, ultimate load $P_{\mathrm{u}}$, and maximum load $P_{\max }$, especially in the groups using acryl. For Group C, the above four parameters, the ratios standardized with group A were 2.04, 1.73, 1.50 , and 1.44, respectively. In the case of urethane, the values also increased. The ratios of group $E$ for the four parameters were 1.91, 1.38, 1.17, and 1.17, respectively. The results indicate that the type of resin showed a stronger strengthening effect. It is assumed that the urethane used in this study had an evaporation residue of $40 \%$, and a large lumen existed when curing was complete. The validity of this assumption is confirmed by the SEM image reported in a previous study [9]. The higher ratios for $K$ and $P_{\mathrm{y}}$ strongly reflect the mechanical properties of the wood surface, because the embedment of the bolt was concentrated in the surface part of the wood for small values of slip. When the slip reached a value around $P_{\mathrm{u}}$, embedment also occurred into the inner part of the wood. The decrease in load was caused by splitting, as shown in Fig. 9a. The values of $P_{\max }$ were mainly determined by the splitting properties, and there was a lower strengthening effect. For an incision depth of $4 \mathrm{~mm}$ (groups B and D), increments in the selected parameters were also observed; however, the ratios were lower than those for a depth of $10 \mathrm{~mm}$. A decrease in slip was observed in the impregnated groups. For example, the ratios of slip at maximum load $\delta_{\max }$ of groups $\mathrm{C}$ and $\mathrm{E}$ are 0.56 and 0.60 , respectively. It is assumed that the resin impregnation reduces the flexibility of wood cells against external forces and causes fracture at a lower level of slip. As a result, energy $S$ was also reduced to almost half of group A for an impregnation depth of $10 \mathrm{~mm}$.

In the groups loaded perpendicular to the grain (Fig. 11b), the differences in stiffness $K$ and yield load $P_{\mathrm{y}}$ due to impregnation are clear. The ratios for group $\mathrm{H}$, for example, are 1.66 and 1.20 for $K$ and $P_{\mathrm{y}}$, respectively. The ratios were lower than those of the groups loaded parallel to the grain. The reason for this is that the resin mainly spreads along the longitudinal direction in wood, which causes a high strengthening effect when the load acts parallel to the grain, but a low strengthening effect when the load acts perpendicular to the grain. It is assumed that if the incision area is large in the transverse direction, a high strengthening effect will be observed in the groups loaded perpendicularly. Slight improvement was observed in ultimate load $P_{\mathrm{u}}$ and no improvement was observed in maximum load $P_{\max }$. The reason for this is that the decrease of load is dominated by the start of splitting failure, as shown in the description of the groups loaded parallel to the grain and Fig. 9b. The ratios of slip at the maximum load $\delta_{\max }$ of groups $\mathrm{H}$ and J are 0.65 and 0.70 , respectively, which shows less reduction than for groups loaded in parallel.

\section{Conclusion}

To strengthen the lateral resistance of bolted joints, the resin was impregnated into the wood surface. This study used two types of resins: acrylic monomer and urethane prepolymer. For curing, the former requires heat, and the 
Table 3 Characteristics values obtained with a perfect elasto-plastic model

\begin{tabular}{|c|c|c|c|c|c|c|c|c|}
\hline Group & $K(\mathrm{kN} / \mathrm{mm})$ & $P_{\mathrm{y}}(\mathrm{kN})$ & $\delta_{y}(\mathrm{~mm})$ & $P_{\mathrm{u}}(\mathrm{kN})$ & $\delta_{\mathrm{u}}(\mathrm{mm})$ & $P_{\max }(\mathrm{kN})$ & $\delta_{\max }(\mathrm{mm})$ & $S(\mathrm{kN} / \mathrm{mm})$ \\
\hline \multicolumn{9}{|l|}{ A } \\
\hline Ave. & 2.56 & 14.28 & 5.62 & 23.17 & 41.39 & 25.22 & 28.16 & 859.4 \\
\hline S.D. & 0.27 & 0.61 & 0.51 & 1.12 & 11.89 & 1.20 & 2.41 & 298.8 \\
\hline \multicolumn{9}{|l|}{ B } \\
\hline Ave. & 3.56 & 20.48 & 6.06 & 28.11 & 26.68 & 29.80 & 21.36 & 632.1 \\
\hline S.D. & 0.70 & 1.82 & 1.94 & 0.96 & 5.92 & 1.88 & 4.90 & 168.6 \\
\hline \multicolumn{9}{|l|}{ C } \\
\hline Ave. & 5.22 & 24.76 & 5.23 & 34.80 & 17.46 & 36.25 & 15.89 & 473.0 \\
\hline S.D. & 1.62 & 3.50 & 2.18 & 3.52 & 2.05 & 0.88 & 2.05 & 84.3 \\
\hline \multicolumn{9}{|l|}{ D } \\
\hline Ave. & 3.12 & 16.55 & 5.40 & 23.38 & 33.27 & 25.17 & 22.56 & 685.6 \\
\hline S.D. & 0.45 & 1.24 & 0.84 & 0.96 & 10.33 & 1.12 & 2.23 & 219.4 \\
\hline \multicolumn{9}{|l|}{ E } \\
\hline Ave. & 4.90 & 19.73 & 4.09 & 27.14 & 18.48 & 29.39 & 16.93 & 422.4 \\
\hline S.D. & 0.74 & 2.10 & 0.64 & 1.54 & 6.91 & 1.35 & 6.44 & 168.3 \\
\hline \multicolumn{9}{|l|}{ F } \\
\hline Ave. & 3.38 & 12.70 & 3.78 & 19.02 & 28.96 & 22.61 & 24.48 & 496.2 \\
\hline S.D. & 0.34 & 0.88 & 0.43 & 1.01 & 1.93 & 0.94 & 2.25 & 38.9 \\
\hline \multicolumn{9}{|l|}{ G } \\
\hline Ave. & 4.74 & 13.85 & 3.05 & 19.73 & 22.84 & 21.89 & 18.11 & 408.0 \\
\hline S.D. & 0.84 & 1.49 & 0.91 & 1.18 & 2.77 & 1.33 & 3.79 & 49.3 \\
\hline \multicolumn{9}{|l|}{$\mathrm{H}$} \\
\hline Ave. & 5.60 & 15.21 & 2.80 & 20.91 & 21.67 & 22.61 & 15.97 & 414.3 \\
\hline S.D. & 0.88 & 1.69 & 0.68 & 1.01 & 1.92 & 1.19 & 4.62 & 51.1 \\
\hline \multicolumn{9}{|l|}{ । } \\
\hline Ave. & 4.11 & 14.33 & 3.65 & 19.44 & 26.16 & 21.76 & 21.57 & 462.8 \\
\hline S.D. & 0.84 & 1.32 & 1.00 & 1.85 & 2.92 & 2.01 & 2.29 & 87.1 \\
\hline \multicolumn{9}{|l|}{ J } \\
\hline Ave. & 5.30 & 17.63 & 3.38 & 21.25 & 20.50 & 22.27 & 17.24 & 393.7 \\
\hline S.D. & 0.95 & 1.57 & 0.49 & 1.55 & 1.77 & 1.53 & 1.18 & 57.3 \\
\hline
\end{tabular}

$K$ : stiffness, $P_{\mathrm{y}}$ : yield load, $\delta_{\mathrm{y}}:$ slip at yielding, $P_{\mathrm{u}}$ : ultimate load, $\delta_{\mathrm{u}}:$ slip at ultimate load, $P_{\max }$ : maximum load, $\delta_{\max }:$ slip at maximum load, $S:$ energy
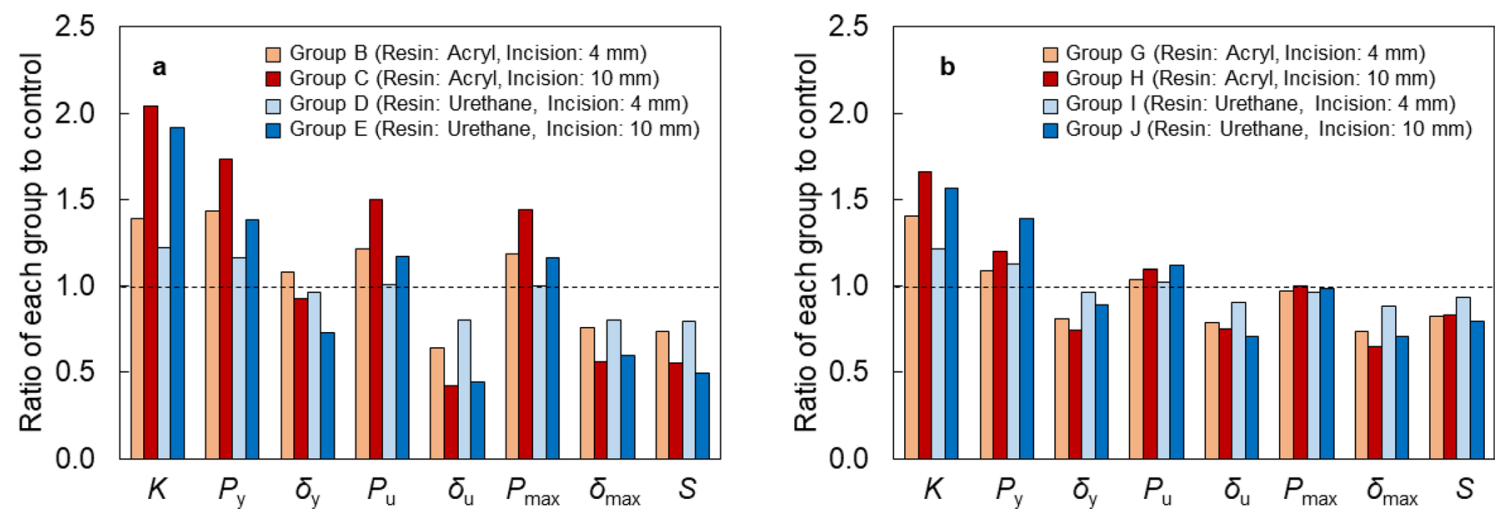

Fig. 11 Ratio for evaluating the strengthening effect calculated by dividing properties of impregnated group by control group. a Groups loaded parallel to the grain. $\mathbf{b}$ Groups loaded perpendicular to the grain 
latter requires time. The effect of incision depth was also investigated. Lateral tests were conducted, and the characteristics were compared with the control group. From the test results, strengthening effects were observed for the impregnated groups. For example, in the specimen groups using acryl loaded parallel to the grain and incised to a depth of $10 \mathrm{~mm}$, the yield load was $24.8 \mathrm{kN}$, which was an increase of $73 \%$ when compared to the control. The maximum load was $36.3 \mathrm{kN}$, which was a $44 \%$ increase. However, the slip at the maximum load was $15.9 \mathrm{~mm}$, which was a decrease of $44 \%$ when compared to the control. The specimen groups using acryl showed a higher strengthening effect than that of urethane. When the incision depth was $4 \mathrm{~mm}$, the strength properties were higher than those of the control group; however, they were lower than the cases of $10 \mathrm{~mm}$ in depth.

Resin spread beyond the incised area in the wood during the impregnation process. It is suggested that the amount of impregnation affects the lateral resistance of the bolted joints, and understanding the mechanism through which the resin spreads in the wood can be an important research topic in the near future. Additionally, an optimization of incising hole density at sapwood and heartwood is also an important. The optimized results will contribute to the excessive impregnation of resins and the shortening of processing time.

\section{Acknowledgements}

This study is financially supported by Emachu Wood Promotion Foundation.

\section{Authors' contributions}

$\mathrm{KO}$ designed and performed the experiments and analyzed the data. SF advised to decide the processing conditions. KO wrote the manuscript in consultation with SF and KK. All authors read and approve the final manuscript.

\section{Funding}

This study is financially supported by Emachu Wood Promotion Foundation.

\section{Availability of data and materials}

All data discussed during this study are included in this published article.

\section{Competing interests}

The authors declare that they have no competing interests.

\section{Author details}

${ }^{1}$ College of Agriculture, Academic Institute, Shizuoka University, 836 Ohya, Suruga-ku, Shizuoka 422-8529, Japan. ${ }^{2}$ Industrial Research Center, Aichi Center for Industry and Science Technology, 1-157-1, Onda-cho, Kariya, Aichi 448-0013, Japan

Received: 21 April 2020 Accepted: 23 September 2020

Published online: 06 October 2020

\section{References}

1. Sawata K (2015) Factors for shear resistance of bolted timber joints. Mokuzai Kogyo 70(1):2-8 (in Japanese)

2. Sawata K (2015) Strength of bolted timber joints subjected to lateral force. J Wood Sci 61(3):221-229

3. Inoue M, Norimoto M, Otsuka Y, Yamada T (1990) Surface compression of coniferous wood lumber I: A new technique to compress the surface layer. Mokuzai Gakkaishi 36(11):969-975

4. Inoue M, Norimoto M, Otsuka Y, Yamada T (1991) Surface compression of coniferous wood lumber II: Permanent set of compression wood by low molecular weight phenolic resin and some physical properties of the products. Mokuzai Gakkaishi 37(3):227-233 (in Japanese)

5. Inoue M, Norimoto M, Otsuka Y, Yamada T (1991) Surface compression of coniferous wood lumber III: Permanent set of the surface compressed layer by a water solution of low molecular weight phenolic resin. Mokuzai Gakkaishi 37(3):234-240 (in Japanese)

6. Yoshihara H, Tsunematsu S (2007) Bending and shear properties of compressed Sitka spruce. Wood Sci Technol 41(2):117-131

7. Laine K, Rautkari L, Hughes M (2013) The effect of process parameters on the hardness of surface densified Scots pine solid wood. Eur J Wood Prod 71(1):13-16

8. Laine K, Segerholm K, Wålinder M, Rautkari L, Hughes M (2016) Wood densification and thermal modification: hardness, set-recovery and micromorphology. Wood Sci Technol 50(5):883-894

9. Fukuta S, Nomura M, Ikeda T, Yoshizawa M, Yamasaki M, Sasaki Y (2018) UV-laser incisions to apply wood-plastic compositions to wood surfaces. Mokuzai Gakkaishi 64(1):28-35 (in Japanese)

10. Goto K (2006) The standard test methods of joints. In: Architectural Institute of Japan (ed). Standard for structural design of timber structures. Maruzen publishing Co., Ltd. Tokyo (in Japanese).

11. ASTM D5652-15 (2020) Standard test method for single-bolt connections in wood and wood-based products. West Conshohocken, PA

12. Yasumura M (2006) Design of joints. In: Architectural Institute of Japan (ed). Standard for structural design of timber structures. Maruzen publishing Co., Ltd. Tokyo (in Japanese).

13. Yuji I (1995) Impregnation of liquid into wood-structure of pits and improvement technology of liquid penetration. Wood Res Tech Notes 31:11-30 (in Japanese)

14. Working group for revising the manuscript of the allowable stress design for wooden framework method (2017) Committee for revising the allowable stress design for wooden framework method (ed). Allowable stress design for wooden framework method. Japan housing and wood technology center, Tokyo (in Japanese).

15. Wanyama OG, Sawata K, Hirai T, Koizumi A, Sasaki Y (2012) Effective lateral resistance of timber-plywood-timber joints connected with nails. J Wood Sci 58:315-321

16. Ogawa K, Sasaki Y, Yamasaki M (2015) Theoretical modeling and experimental study of Japanese "Watari-ago" joints. J Wood Sci 61:481-491

17. Ogawa K, Harada M, Shibusawa T, Miyamoto K (2018) Single shear properties and deformation behavior of nailed joints using various structural panel materials. Mokuzai Gakkaishi 64(4):139-148 (in Japanese)

18. Ueda R, Sawata K, Takanashi R, Sasaki Y, Sasaki T (2020) Degradation of shear performance of screwed joints caused by wood decay. J Wood Sci 66:42

\section{Publisher's Note}

Springer Nature remains neutral with regard to jurisdictional claims in published maps and institutional affiliations. 